\title{
A CONDIÇÃO FEMININA DA MULHER NEGRA EM "MARIA", DE CONCEIÇÃO EVARISTO, E "NO SEU PESCOÇO", DE CHIMAMANDA NGOZI ADICHIE
}

\author{
Flávio Pereira Camargo \\ Lorrany Andrade da Cruz
}

A nossa escrivência não pode ser lida como histórias para 'ninar os da casa grande' e sim para incomodá-los em seus

sonos injustos.

Conceição Evaristo

Resumo: Neste artigo temos como objetivo investigar como mulheres negras de diferentes diásporas africanas experienciam e manifestam (no sentido de manifesto, denúncia), em seu tempo-lugar, opressões estruturais relacionadas ao colonialismo, tais como o racismo, o sexismo e o classicismo (KILOMBA, 2019), rompendo com o discurso hegemônico e com a ótica colonizadora sobre seus corpos, suas identidades e sua sexualidade (COLLINS apud BERTH, 2018). Para tanto, pretendemos analisar as vivências distintas dessas personagens, tendo em vista o contexto sociocultural brasileiro, no conto "Maria", de Olhos d'água (2016), de Conceição Evaristo, e o contexto diaspórico entre Nigéria e Estados Unidos no conto "No seu pescoço", de No seu pescoço (2017), de Chimamanda Adichie, observando como as personagens femininas são silenciadas e como enfrentam esse silenciamento. A escolha dessas autoras e de suas obras decorre de uma necessidade latente na contemporaneidade de um olhar sobre as questões de gênero interseccionadas com raça e classe sem a necessidade de hierarquizálas (RIBEIRO, 2019), pois essas categorias se intercruzam na perspectiva do feminismo negro, buscando romper com uma cisão criada por uma sociedade desigual, patriarcalista e heterossexista.

Palavras-chave: Literatura negra. Feminismo negro. Mulheres negras. Opressões estruturais.

Abstract: In this paper we aim to investigate how black women from different African diasporas experience and manifest (in the sense of manifest, denunciation), in their time-place, structural oppressions related to colonialism, such as racism, sexism, and classicism (KILOMBA, 2019), breaking with the hegemonic discourse and the 
colonizing perspective on their bodies, their identities and their sexuality (COLLINS apud BERTH, 2018). In order to do so, we intend to analyze the different experiences of these characters, considering the Brazilian sociocultural context in the short story "Maria", from the work Olhos d'Agua (2016), by Conceição Evaristo, and the diasporic context between Nigeria and the United States in the short story "The Thing Around Your Neck", from The Thing Around Your Neck (2017), by Chimamanda Adichie, observing how female characters are silenced and how they face this silencing. The choice of these authors and their works stems from a latent need in the contemporary perspective of looking at gender issues intersected with race and class without the need to hierarchize them (RIBEIRO, 2019), as these categories intersect in the perspective of feminism black, seeking to break with a split created by an unequal, patriarchal and heterosexist society.

Keywords: Black literature. Black feminism. Black women. Structural oppressions.

\section{CONSIDERAÇÕES INICIAIS}

Durante muito tempo, foi negado às pessoas negras, em especial às mulheres negras, o direito de serem sujeitos, ou seja, o direito de contarem as próprias histórias e vivências, sendo fadadas a ter suas identidades objetificadas, isto é, reduzidas a uma existência de um objeto descrito e representado pelo dominante, retiradas de sua subjetividade (KILOMBA, 2019). Antes disso, foi-lhes negado o direito à existência e à humanidade. No que diz respeito à literatura, além de suas produções serem invisibilizadas, essas mulheres eram vistas sob uma ótica colonizadora e estereotipada. Conceição Evaristo (2009), ao fazer um estudo sobre os estereótipos de negros presentes na literatura brasileira, 
afirma que os personagens negros são vistos e representados, em sua maioria, como sujeitos afásicos ou detentores de uma linguagem estranha, incapaz de apreender o idioma branco. No caso das mulheres negras,

a ficção ainda se ancora nas imagens de um passado escravo, em que a mulher negra era considerada só como um corpo que cumpria as funções de força de trabalho, de um corpo-procriação de novos corpos para serem escravizados e/ou de um corpo-objeto de prazer do macho senhor. (EVARISTO, 2009, p. 23)

Essa objetificação do corpo da mulher negra ocorria por ela ser a antítese de masculinidade e de branquitude, pois, como afirma Grada Kilomba (apud RIBEIRO, 2019), as mulheres negras estão em um lugar de subalternidade ainda mais difícil de ser superado. Dessa forma, por muito tempo suas vozes foram silenciadas e desumanizadas, negando-Ihes o direito à humanidade. "Por serem vítimas de opressões intercruzadas, as mulheres negras encontram-se em um 'não lugar', mas mais além: consegue[m] observar o quanto esse não lugar pode ser doloroso e igualmente atenta[s] também no que pode ser um lugar de potência" (RIBEIRO, 2019, p. 46).

Conceição Evaristo, escritora brasileira, e Chimamanda Adichie, escritora nigeriana, são mulheres negras que partem 
desse lugar de potência e quebram a ótica colonizadora tida sobre si por meio da produção literária. Por ambas estarem nesse lugar de sujeito-mulher-negra, nota-se que, em suas obras, existem semelhanças nas experiências vivenciadas pelas personagens femininas, apesar dos distintos contextos implicarem em certas diferenças. Desse modo, pretendemos, neste trabalho, investigar como mulheres negras de diferentes diásporas africanas experienciam e manifestam (no sentido de manifesto, denúncia), em seu tempo-lugar, opressões estruturais relacionadas ao colonialismo, tais como o racismo, o sexismo e o classicismo (KILOMBA, 2019), considerando o modo como as personagens femininas são silenciadas e como enfrentam esse silenciamento. Neste sentido, analisamos as vivências distintas dessas mulheres, tendo em vista o contexto sociocultural brasileiro, o conto "Maria", de Olhos d'água (2016), de Conceição Evaristo, e o contexto diaspórico entre Nigéria e Estados Unidos a narrativa "No seu pescoço", incluída em No seu pescoço (2017), de Chimamanda Adichie.

Para alcançar esses objetivos, partimos de uma pesquisa bibliográfica, com base no pensamento feminista negro, que propõe um olhar sobre as questões de gênero interseccionadas com as de raça e classe sem a necessidade 
de hierarquizá-las, como nos diz Djamila Ribeiro (2019). Dessa forma, inicialmente, faremos uma incursão pelo feminismo negro, além da abordagem do conceito de interseccionalidade, lugar de fala e empoderamento, tendo em vista o silenciamento epistêmico imposto às pessoas negras, em especial às mulheres negras. Além disso, faremos uma breve retomada dos conceitos de pós-colonialidade e diáspora, a partir dos estudos póscoloniais de Claudio Braga (2014) acerca da obra de Chimamanda Adichie. Além disso, julgamos crucial uma reflexão acerca de alguns conceitos-chave como o racismo estrutural e institucional no contexto brasileiro para a análise de "Maria", de Olhos d'água (2016). As análises desses textos, considerando suas especificidades, com o objetivo de analisar como as personagens femininas experienciam e manifestam as opressões que sofrem, assim como enfrentam o silenciamento imposto a elas, nos permitirá elaborar uma reflexão sobre a importância de mulheres negras se autodeterminarem, para que possam se emancipar e reconstruir seu lugar dentro da sociedade, além de construir novos lugares reivindicando para si o seu lugar de potência, que é seu por direito e pertencimento. 


\section{FEMINISMO NEGRO: UMA DISCUSSÃO NECESSÁRIA}

As mulheres negras estão em uma situação de dupla subalternidade por estarem inseridas em uma sociedade desigual, racista e sexista, que lhes nega o lugar de sujeito, sendo reduzidas, muitas vezes, à objetificação. Daí a necessidade de um olhar e de uma discussão teórico-crítica acerca do feminismo negro e do lugar dessas mulheres na sociedade e na literatura. Para Djamila Ribeiro,

Kilomba sofistica a análise sobre a categoria do Outro quando afirma que mulheres negras, por serem nem brancas e nem homens, ocupam um lugar muito difícil na sociedade supremacista branca por serem uma espécie de carência dupla, a antítese de branquitude e masculinidade. Nessa análise, percebe 0 status das mulheres brancas como oscilantes, pois são mulheres, mas são brancas, do mesmo modo, faz a mesma análise em relação aos homens negros, pois esses são negros, mas homens. Mulheres negras, nessa perspectiva, não são nem brancas e nem homens, e exerceriam a função de Outro do Outro. (2019, p. 38, grifo da autora)

Tendo em vista essa situação, percebemos que essas mulheres são desumanizadas e suas vozes silenciadas pela estrutura da sociedade. Até mesmo no movimento feminista, que busca a igualdade de gênero, porém, não considera as especificidades de mulheres não brancas. 
Angela Davis, em sua obra Mulheres, raça e classe (2016), publicada originalmente na década de 1980, lança um olhar sobre o sufrágio feminino, o racismo e a luta de classes nos Estados Unidos, tendo como centro a mulher negra e sua importância nesse contexto. Pelo próprio título, notamos uma visão interseccional da autora que observa como as opressões sexistas, racistas e classistas atingem as mulheres negras: "a condição de mulheres que sofriam com a combinação das restrições de sexo, raça e classe, elas tinham um poderoso argumento pelo direito ao voto" (DAVIS, 2016, p. 149). Em relação ao movimento sufragista, a escritora nota o crescente racismo, visto que esse atendia somente a necessidade de mulheres brancas da classe média, excluindo as operárias e principalmente as mulheres negras: "o racismo operava de forma tão profunda no interior do movimento sufragista feminino que as portas nunca se abriram de fato às mulheres negras" (DAVIS, 2016, p. 149).

Devido a isso, surgiu o feminismo negro, dado que o feminismo pretensamente universal não atendia às necessidades de mulheres que não eram brancas, como observa Djamila Ribeiro:

Teorias feministas brancocêntricas, mas que se pretendem universais, por mais que possuam uma posição política de emancipação, na ação não realizam seu 
objetivo, pois negam as especificidades de outras mulheres, representando assim somente mulheres em situações de algum privilégio social. (2016, p. 22)

Nesse viés, Ribeiro retoma o pensamento de Lélia Gonzalez que reflete sobre a ausência de mulheres negras e indígenas no feminismo hegemônico, além de criticar "essa insistência das intelectuais e ativistas em somente reproduzirem um feminismo europeu, sem dar a devida importância sobre a realidade dessas mulheres em países colonizados" (RIBEIRO, 2019, p. 24). Dessa maneira, Gonzalez defende um feminismo afro-latino-americano, colocando em evidência que essas mulheres compartilham mais do que experiências baseadas na escravidão, no racismo e no colonialismo: elas compartilham processos de resistências (apud RIBEIRO, 2019).

Pensando no contexto brasileiro, Sueli Carneiro (2016) expõe a necessidade de enegrecer o feminismo, expressão que busca assinalar "a identidade branca e ocidental da formulação clássica feminista, de um lado; e, de outro, revelar a insuficiência teórica e prática político para integrar as diferentes expressões do feminino construídas em sociedades multirraciais e pluriculturais" (CARNEIRO, 2016, p. 151). Essa perspectiva, segundo Carneiro, "emerge da 
condição específica do ser mulher, negra e, em geral, pobre", a qual condena "as mulheres negras a uma situação perversa e cruel de exclusão e marginalização sociais" (2016, p. 165).

Portanto, o feminismo negro não busca trazer cisões ou separações, porque

ao nomear as opressões de raça, classe e gênero, entende-se a necessidade de não hierarquizar opressões, de não criar, como diz Angela Davis, em Mulheres negras na construção de uma nova utopia, "primazia de uma opressão em relação a outras". Pensar em feminismo negro é justamente romper com a cisão criada numa sociedade desigual, logo é pensar projetos, novos marcos civilizatórios para que pensemos em um novo modelo de sociedade. (RIBEIRO, 2019, p. 13-14, grifo da autora)

Assim, como diz Joice Berth (2018), a perspectiva feminista negra visa superar as opressões estruturais e ampliar o conceito de humanidade. Considerando que o feminismo negro é essencialmente interseccional, faz-se necessário abordar esse conceito, assim como os conceitos de lugar de fala e empoderamento, tendo em vista que a situação específica de mulheres negras silencia suas vozes, saberes e produções intelectuais. 


\subsection{INTERSECCIONALIDADE, LUGAR DE FALA E EMPODERAMENTO: FERRAMENTAS DE COMBATE AO SILENCIAMENTO EPISTÊMICO}

O termo interseccionalidade é inaugurado em 1989, por Kimberlé Crenshaw, ao publicar em inglês o artigo "Demarginalizing the intersection of race and sex: feminist critique of antidiscrimination doctrine, feminist theory and antiracist politics" (AKOTIRENE, 2019). Porém, em "Racismo e sexismo na cultura brasileira", de 1984, e em "Por um feminismo afro-latino-americano", de 1988, Lélia Gonzalez apontou a intersecção entre gênero, raça e classe, inclusive, chamando a atenção para a maior dificuldade da inserção trabalhista de lésbicas negras. Assim, essa autora contribuiu para a construção desse conceito teórico, antes de ele ser nomeado e difundido por Crenshaw. Isso corrobora com o pensamento de Ribeiro (2018), ao afirmar que várias feministas negras já se utilizavam de uma análise interseccional antes da inauguração do termo (RIBEIRO, 2018).

De acordo com Kimberlé Crensaw,

a interseccionalidade permite-nos enxergar a colisão das estruturas, a interação simultânea das avenidas identitárias, além do fracasso do feminismo em contemplar mulheres negras, já que reproduz o racismo. Igualmente, o movimento negro falha pelo 
caráter machista, oferece ferramentas metodológicas reservadas às experiências apenas do homem negro. (apud AKOTIRENE, 2019, p. 19)

Neste sentido, o conceito de interseccionalidade nos permite compreender como as opressões estruturais oriundas de sociedades de matriz colonial se intercruzam e interagem simultaneamente, dando
instrumentalidade teórico-metodológica à inseparabilidade estrutural do racismo, capitalismo e cisheteropatriarcado - produtores de avenidas identitárias em que mulheres negras são repetidas vezes atingidas pelo cruzamento e sobreposição de gênero, raça e classe, modernos aparatos coloniais. (AKOTIRENE, 2019, p. 19)

Entretanto, a interseccionalidade é pensada pelas mulheres negras, marcadamente as feministas negras, de forma mais abrangente, uma vez que é tida como ferramenta essencial de estratégia e luta política (BERTH, 2018). Segundo Berth, nenhum outro grupo é tão necessitado "desses processos e de sua aplicabilidade fática quanto o de mulheres negras" (2018, p. 63). Devido a isso, Akotirene (2019) acredita que a interseccionalidade deve ser mencionada como sugestão das feministas negras e não ser dita como feminismo interseccional, pois elas são proponentes da interseccionalidade enquanto metodologia, 
visando combater discriminações multideterminadas, pautadas, de início, no binômio raça-gênero.

Considerando a situação das mulheres negras de dupla subalternidade pela intersecção de opressões de raça e de gênero, notamos o silenciamento epistêmico, uma vez que o modelo eurocêntrico branco, por ter poder na estrutura social, também determina quais saberes são legitimados. Dessa maneira, o modelo valorizado e universal de ciência é branco, pois o privilégio social equivale ao privilégio epistêmico (RIBEIRO, 2019). Essa hierarquização confere ao pensamento moderno ocidental a exclusividade do que seria conhecimento válido, "estruturando-o como dominante e, assim, inviabilizando outras experiências do conhecimento" (RIBEIRO, 2019, p. 24), tendo como consequência a legitimação da explicação epistemológica eurocêntrica como superior.

Logo,

as experiências desses grupos localizados socialmente de forma hierarquizada e não humanizada faz com que as produções intelectuais, saberes e vozes sejam tratadas de modo igualmente subalternizado, além das condições sociais os manterem num lugar silenciado estruturalmente. (RIBEIRO, 2019, p. 63)

Sob esse viés, as possibilidades de mulheres negras se fazerem ouvir é ainda menor. Perante essa perspectiva, se 
faz pertinente abordar as reflexões de Ribeiro (2019) sobre o lugar de fala. De acordo com a filósofa, o lugar social que ocupamos nos faz ter vivências e perspectivas diferentes, e quando falamos, o fazemos a partir desse locus social. Além disso, esse lugar pode silenciar determinadas vozes e dar legitimidade a outras. Ou seja, há uma hierarquização de saberes e também um silenciamento daqueles que estão em um lugar de subalternidade na estrutura da sociedade, a exemplo das mulheres negras. Dessa maneira, há a promoção de uma voz única, pretensamente universal, falando sobre vozes silenciadas estruturalmente.

Em vista disso, Ribeiro (2019) pensa esse lugar de fala "como [possibilidade para] refutar a historiografia tradicional e a hierarquização de saberes consequente da hierarquia social. Quando falamos de direito à existência digna, à voz, estamos falando de locus social, de como esse lugar imposto dificulta a possibilidade de transcendência" (RIBEIRO, 2019, p. 64). Assim, essa teoria do ponto de vista feminista e lugar de fala nos faz enxergar que a visão da historiografia tradicional, feita a partir da perspectiva de homens brancos, não é universal e tampouco única, mas tem relação com o locus social, que é metáfora do poder. Logo, ao pensar em lugar de fala, criamos a possibilidade de abrir caminhos 
para que vozes subalternas possam ser ouvidas, além de se refutar uma visão universal de mulher e de negritude (RIBEIRO, 2019).

Segundo Ribeiro (2019), para possibilitar voz e visibilidades a esses sujeitos, que foram considerados implícitos dentro da normatização hegemônica (masculina e branca), é necessário promover uma multiplicidade de vozes através do "deslocamento do pensamento hegemônico e a ressignificação das identidades, sejam de raça, gênero, classe para que se pudesse construir novos lugares de fala" (RIBEIRO, 2019, p. 42-43), e, assim, romper com o regime de autorização discursiva, ou seja, que apenas uma voz seja autorizada a falar e dar sua perspectiva. Ao se alcançar isso, ampliamos o conceito de humanidade e damos um passo em direção a uma sociedade mais igualitária, já que as particularidades dos sujeitos oprimidos serão consideradas a partir de seu próprio ponto de vista e de suas vivências.

Notamos, a partir disso, o elo entre lugar de fala e o feminismo negro, relação realçada por Ribeiro (2019) ao fazer uma breve incursão pelo pensamento de feministas negras no início da sua obra Lugar de fala. Para a autora, as "mulheres negras estavam produzindo insurgências contra 
o modelo dominante e promovendo disputas de narrativas" (2019, p. 23) há muito tempo, a exemplo de Sojourner Truth, com seu discurso "E não sou eu uma mulher?", em 1851. Essas contra-narrativas são formas de reivindicar diferentes pontos de análise e marcar o lugar de fala de quem os propõe, objetivos alinhados com o Feminismo Negro (RIBEIRO, 2019).

A partir dessas reflexões, entendemos a importância de mulheres negras se autodefinirem para que possam se emancipar e ressignificar seu lugar dentro da sociedade, sendo uma estratégia importante para combater a 'intervenção da mulher negra' pela ótica colonizadora (COLLINS apud BERTH, 2018 , p. 74). Desse modo, "a mulher negra, ao passar a falar de si, poderia contribuir por meio de sua perspectiva com a teoria feminista por oferecer novas possibilidades de enfrentamento e ações políticas. Por descentrar uma visão que era brancocêntrica, mas tida como universal" (RIBEIRO, 2016, p. 23). A criação, pelas feministas negras, dos conceitos aqui abordados já indica uma ação política de resistência.

No que diz respeito a essas novas possibilidades de enfrentamento de opressões estruturais, Joice Berth (2018) aponta o empoderamento como uma ferramenta para tal. Em seu trabalho, o empoderamento "não visa retirar poder 
de um para dar a outro a ponto de se inverter os polos de opressão, mas sim uma postura de enfrentamento da opressão para a eliminação da situação injusta e equalização de existências em sociedade" (BERTH, 2018, p. 16).

Nesse sentido, a autora faz uma relação entre o empoderamento e o lugar de fala, no sentido de ambos os conceitos serem instrumentos na luta pelo direito à voz e à existência, além de complementar os vazios deixados pelo pensamento hegemônico considerado como universal. $O$ empoderamento (assim como o lugar de fala) se relaciona estreitamente com o Feminismo Negro, já que esse movimento o resgatou e o ressignificou. Neste sentido,

tendo como fator limítrofe, a permanência na base da pirâmide social, esse resgate mostra-se fundamental para nossa movimentação na luta pela quebra da formação hegemônica dessa pirâmide. Podemos chamar de resgate, pois não é novidade para os movimentos de mulheres negras, a necessidade de busca por processo de empoderamento como condição de sobrevivência. (BERTH, 2018, p. 103, grifo da autora)

Dessa maneira, o empoderamento torna-se necessário para a equalização de existências na sociedade e para a sobrevivência física e mental de mulheres negras. No que diz respeito às produções literárias, notamos esse silenciamento 
epistêmico de pessoas negras, mas também a possibilidade de afirmação de um contra-discurso através da literatura negra. Nesse viés, Conceição Evaristo (2009) reflete sobre os estereótipos de negros presentes na literatura brasileira, defendendo, ainda, a necessidade de "um contra-discurso à literatura produzida pela cultura hegemônica, [uma vez que] os textos afro-brasileiros surgem pautados pela vivência de sujeitos negros/as na sociedade brasileira [...] trazendo experiências diversificadas, desde o conteúdo até os modos de utilização da língua" (EVARISTO, 2009, p. 27). Em relação a essas vivências, Conceição Evaristo cunha o conceito de "escrevivência":

Ele [o texto] tem uma autoria, um sujeito, homem ou mulher, que com uma subjetividade própria vai construindo sua escrita, vai inventando, criando o ponto de vista do texto. Em síntese, quando escrevo, quando invento, quando crio a minha ficção, não me desvencilho de um corpo-mulhernegra em vivência e que por esse ser o meu corpo, e não outro, vivi e vivo experiências que um corpo não negro, não mulher, jamais experimenta. (EVARISTO, 2009, p. 18)

Dessa forma, as vivências de Evaristo, em seu corpomulher-negra, faz com que seu texto literário seja traçado a partir das particularidades e da consciência de um sujeito marcado pela dupla subalternidade. Assim, a 
Escrevivência parte da consciência do vivido que faz da escrita compromisso como um lugar de autoafirmação das especificidades daquele que escreve (ALVES; SOUZA, 2018). Nesse sentido, nas próximas seções, analisamos o conto "No seu pescoço", da obra homônima de Chimamanda Adichie, e o conto "Maria", de Olhos d'água, de Conceição Evaristo, haja vista as especificidades de cada contexto. Após essa análise, apontaremos as confluências e divergências das experiências de opressões das personagens femininas, tendo em vista a perspectiva feminista negra (já que essa considera a sobreposição de opressões) e a sua relação com os conceitos de interseccionalidade, empoderamento e lugar de fala, importantes ferramentas de combate ao silenciamento epistêmico. A partir dessa leitura, será possível elaborar uma reflexão sobre a importância de duas mulheres negras e escritoras que rompem com a ótica colonizadora tida sobre si, provocando fissuras no cânone literário.

\section{A CONDIÇÃO FEMININA DA MULHER NEGRAAFRICANA NOS ESTADOS UNIDOS: DIÁSPORA E PÓS-COLONIALIDADE EM “NO SEU PESCOÇO”}

Chimamanda Ngozi Adichie nasceu em Enugu, Nigéria, em 1977 e pertence ao povo Ibo. Aos 16 anos, muda-se para os Estados Unidos para estudar comunicação. É Graduada em Comunicação pela Universidade Drexel e em Ciência 
Política pela Universidade Estadual de Connecticut. Além disso, tem Mestrado em Criação Literária na Universidade John Hopkins e em Estudos Africanos na Universidade de Yale. O seu primeiro romance Hibisco roxo, foi publicado em 2003. Desde então, escreveu mais dois romances Meio sol amarelo (2006), Americanah (2013) e uma coletânea de contos, No seu pescoço (2009). Suas obras já receberam mais de 14 prêmios, além de diversas indicações. Também é conhecida por duas miniconferências: The danger of a single story [O perigo de uma história única] e We all should be feminists [Sejamos todos feministas], promovidas pelo grupo sem fins lucrativos Technology, Entertainment, Design (TED) e divulgada para milhões de pessoas através de plataformas de vídeos, como o Youtube; a primeira, de 2009, e a segunda, de 2013 (BRAGA; 2014, 2019).

No seu pescoço (2009) reúne 12 dentre seus vários contos, antes publicados de modo separado em revistas literárias e jornais, sendo narrativas ambientadas tanto na Nigéria quanto nos Estados Unidos, remetendo a uma dialética diaspórica (BRAGA, 2014). Segundo Claudio Braga (2014), as cinco narrativas que se passam nos Estados Unidos são intercaladas às que se situam na Nigéria, indicando que os doze contos aparecem dispostos de modo alternado em 
termos de espaço ficcional. De acordo com o autor, essa organização, tanto da estrutura da coletânea, quanto dos enredos dos contos, nos permite confrontar a tensão entre o lugar de origem e o país hospedeiro, assim como enfatizam que "o movimento diaspórico deixa de ser apenas geográfico para existir no âmbito simbólico da ficção, com retornos possíveis de ocorrer na imaginação, nos conflitos interiores de cada um" (BRAGA, 2014, p. 52).

Tendo em vista esse movimento diaspórico nas narrativas e na ficção de Adichie, retomaremos brevemente os conceitos de diáspora e pós-colonialidade, conceitos operacionais necessários para a leitura do conto "No seu pescoço", pois nesta narrativa a autora explora a vivência de Akunna, uma jovem nigeriana, nos Estados Unidos.

Primeiramente, o termo diáspora está ligado à ideia de espalhamento, dispersão. "Safran (1991) se dedica à tarefa de definir a diáspora, ao descrever comunidades expatriadas que teriam determinadas características" (SAFRAN apud BRAGA, 2014, p. 32), dentre elas, a dispersão de um centro para duas ou mais regiões periféricas ou estrangeiras; compromisso com a manutenção ou restauração da terra natal, sua segurança e prosperidade. Ademais, segundo Braga (2014), Cohen (1999) inclui três novos aspectos em 
relação aos de Safran (1991), sendo um deles o fato de que a diáspora envolve "uma expansão para além de uma terra natal à procura de trabalho, em busca de comércio ou por futuras ambições coloniais" (COHEN apud BRAGA, 2014, p. 33). No caso do continente africano, pensa-se na "velha diáspora africana", ou seja, o tráfico de pessoas e as "novas diásporas africanas" oriundas da descolonização política ou a independência das ex-colônias, relacionadas à condição contemporânea da pós-colonialidade (BRAGA, 2019). Entre essas novas diásporas está a nigeriana.

A Nigéria, ex-colônia britânica, é uma nação jovem e complexa, com mais de 162 milhões de habitantes, localizada na África ocidental. De acordo com o IBGE (2011), seu PIB é de 196 milhões de dólares, cerca de 10 vezes menor que o brasileiro. As condições econômicas precárias têm como resultado a falta de oportunidades de trabalho, talvez a causa principal para a diáspora nigeriana contemporânea, além da violência e a instabilidade social provocadas por tensões religiosas entre grupos étnicos como ibos, iorubás e haussás, entre outros (BRAGA, 2014).

Essa nova diáspora se relaciona com a condição de póscolonialidade, que é definida por Braga como

uma condição contemporânea multifacetada, surgida a partir da extinção da colonização 
formal, em parte determinada pelo sistema mundial de Estados-nações, que se caracteriza pela presença persistente e até o reforço de preceitos e valores culturais disseminados por colonizadores, porém hibridizados de maneira complexa tanto com preceitos e valores précoloniais - que resistiram, apesar da violência da colonização -, como também com preceitos e valores contemporâneos de culturas terceiras. (BRAGA, 2019, p. 40)

Além disso, marcam essa condição mundial contemporânea a intensa inquietude e mobilidade, que se dá nos deslocamentos e relocações, tanto geográficos e físicos como também simbólicos e abstratos, oriundos da reconfiguração estabelecida pelo processo político de independência dos países colonizados (BRAGA, 2019).

Essas duas condições (de diáspora e pós-colonialidade) são relevantes na literatura de Adichie. Segundo Braga (2019), em Americanah, tem-se em Ifemelu e nos taxistas nigerianos o sujeito pós-colonial diaspórico: são sujeitos imigrantes, que vêm da Nigéria, sendo assim, carregam as marcas do presente diaspórico e do passado colonial (BRAGA, 2019). Esse sujeito também se faz presente nos contos da autora ambientados nos Estados Unidos, como ocorre em "No seu pescoço".

Em primeiro lugar, no início da narrativa percebemos uma visão idealizada e ingênua dos Estados Unidos (uma 
visão comercializada pelos próprios estadunidenses em seus produtos culturais), país visto como a terra das oportunidades, como vemos no fragmento abaixo:

Você pensava que todo mundo nos Estados Unidos tinha um carro e uma arma; seus tios, tias e primos pensavam o mesmo. Logo depois de você ganhar a loteria do visto americano, eles the disseram: daqui a um mês, você vai ter um carro grande. Logo, uma casa grande. Mas não compre uma arma como aqueles americanos. (ADICHIE, 2017, p. 125)

Essa perspectiva do "sonho americano" faz com que os parentes de Akunna peçam que ela os envie uma série de presentes - bolsas, sapatos, perfumes. Assim, notamos que a motivação da diáspora é a busca de uma melhor oportunidade de ascensão econômica, e isso se daria, inferimos, por meio do trabalho e do estudo, o que conflui com um dos aspectos citados por Cohen (1999) sobre a diáspora. Quando a jovem chega aos Estados Unidos passa a morar com os tios e seus filhos e também frequenta a faculdade comunitária, onde as garotas tinham uma visão estereotipada e racista de imigrantes africanos:

Elas perguntaram onde você tinha aprendido a falar inglês, se havia casas de verdade na África e se você já tinha visto um carro antes de vir para os Estados Unidos. Olharam boquiabertas para o seu cabelo. Ele fica em pé ou cai quando você solta as tranças? Elas 
queriam saber. Fica todo em pé? Como? Por quê? Você usa pente? Você sorria de um jeito forçado enquanto elas faziam essas perguntas. (ADICHIE, 2017, p. 126)

Essa imagem construída pelas garotas, que não admite a possibilidade de haver carros ou casas no continente africano, é causada pela história única divulgada sobre África, como alerta Chimamanda Adichie em sua conferência "O perigo de uma história única". Essa visão unilateral causa a perpetuação de estereótipos e o apagamento de múltiplas facetas de diversos povos, lugares e culturas. Observamos, ainda, o estranhamento do cabelo afro, visto como algo exótico, uma vez que é afastado da estética europeia/ caucasiana. O cabelo de Akunna não é objeto desses tipos de comentários na Nigéria, país com população negra em sua maior parte, porém, na terra hospedeira, já se torna uma questão, marcando conflitos que passam a existir a partir da diáspora desse sujeito. De acordo com Berth, "temos as intersecções de opressão machista e racista pautando a existência de mulheres negras pois, ao homem negro, algumas cobranças estéticas para a aproximação da imagem do homem caucasiano são facultativas" (2018, p. 94). Desse modo, talvez o cabelo não fosse alvo de perguntas ignorantes se se tratasse de um jovem nigeriano e não de uma mulher. 
Apesar disso, Akunna se sente confortável na casa de seus tios: "Eles falavam igbo e comiam garri de almoço. Era como estar em casa" (ADICHIE, 2017, p. 127). Segundo Braga, "o ambiente acolhedor pressupõe uma condição diaspórica solidária, em que o grupo se encontra unido e harmonioso, até que uma noite o tio desce ao porão onde Akunna dorme" (2014, p. 46). Ele a agarra com força e aperta sua bunda, a assediando sexualmente, deixando implícito que era algum tipo de "pagamento" pela acolhida que deram a ela, pois na "América era dar e receber". Esse assédio marca a questão de gênero, a opressão patriarcal que faz parte da estrutura social e que a atinge em sua condição feminina. Como aponta Akotirene (2019), as mulheres negras são atingidas pela colisão de estruturas e pela interação simultânea de avenidas identitárias. É o que acontece com Akunna desde sua chegada à terra hospedeira, porque além de ser mulher e negra (envolvendo, assim, a interseccionalidade de opressões de raça e gênero), é emigrante do continente africano, marcando-a como estranha e exótica, condição que mulheres afro-estadunidenses, por exemplo, não experienciariam.

Conforme Braga, "a partir do assédio sexual, a ilusão do lar como ambiente de proteção e aconchego se desfaz e o país hospedeiro, para Akunna, fica ainda mais distante 
do idealizado" (2014, p. 47). Logo, as ilusões da jovem se desfazem uma por uma: não houve enriquecimento imediato e, após sair da casa do tio, ela se instala em um pequeno quartinho, trabalha como garçonete com uma renumeração baixa que mal dá para suas despesas (porém, sempre envia metade do salário para os pais na Nigéria) e precisa parar de cursar a faculdade. Esse compromisso da personagem em apoiar seus familiares ao enviar parte de suas economias indica a iniciativa de manutenção da terra natal (SAFRAN apud BRAGA, 2014). Não obstante, Akunna nunca escreve, embora tenha vontade de relatar o que vê, pois não tem dinheiro suficiente para comprar os presentes pedidos pelos parentes. Ela se sente invisível e isolada: "sentir-se ignorada é mais do que a circunstância pessoal de Akunna, verificando-se com frequência na condição diaspórica em que o país hospedeiro não reconhece a presença ou não deseja interagir com as minorias diaspóricas" (BRAGA, 2014 , p. 47). Esse isolamento faz com que ela sinta a "coisa em volta do seu pescoço" (em inglês, o título do conto é "The thing around your neck"), que a sufoca toda noite. Essa expressão "alude ao fato de Akunna não conseguir se expressar oralmente, tampouco por escrito" (BRAGA, 2014, p. 47), assim como o sufoco pelo qual a personagem passa, que a aperta e a incomoda, como um torcicolo. 
A ignorância e a perspectiva unilateral que os estadunidenses médios têm de África é ainda mais perceptível nas falas direcionadas a Akunna pelos clientes do restaurante onde ela trabalha: "Muitas pessoas no restaurante perguntavam quando você tinha chegado da Jamaica, pois achavam que qualquer negro com sotaque estrangeiro era jamaicano. Alguns que adivinhavam que você era africana diziam que adoravam elefantes e queriam fazer um safári" (ADICHIE, 2017, p. 130). Entretanto, um dia aparece um rapaz que a surpreende por não fazer as mesmas perguntas dos outros clientes: perguntou se ela era iorubá ou igbo, e relatou algumas viagens que fizera para a África, demonstrando ser intelectual, porém, não condescendente. Ele (não nomeado na narrativa) a chama para sair algumas vezes, mas ela sempre recusa, até que uma noite ela aceita.

Com o namoro, a coisa em volta do pescoço de Akunna se afrouxa, no entanto, percebemos várias dificuldades no relacionamento, principalmente pelo fato de haver certa dessintonia entre os dois e do estranhamento causado pelo fato de ser um casal interracial. O primeiro problema vem do fato de a jovem ter experiências na Nigéria (de necessidades) que a afastam da realidade vivida por seu namorado, que por vezes não a compreende, tanto por 
estar em um lugar social diferente, de privilégios (como um homem, branco, rico e filho de pais que são professores universitários) quanto pelas diferenças culturais. Por mais que tente, ele não a entende inteiramente. A retomada da terra natal por meio das memórias de Akunna, no âmbito simbólico, como observa Braga (2014), indica que a Nigéria é um lugar de sofrimento e dificuldade, porém, ao mesmo tempo, é "um espaço familiar, conhecido, onde sabem lidar com as adversidades, diferentemente do que ocorre na diáspora" (BRAGA, 2014, p. 38).

Além das adversidades já vistas, há os conflitos que resultam do fato de eles serem um casal interracial: um exemplo relevante é o momento em que um garçom de um restaurante bastante frequentado pelos dois presume que ela não poderia ser namorada dele, apesar de eles se beijarem e estarem sempre juntos. Ele não corrigiu o homem, o que magoou Akunna. Mesmo depois de ela explicar isso, ele não a entendeu. Há, ainda, outras reações semelhantes de estranhamento em vista de um casal interracial, como observamos abaixo:

Pela reação das pessoas, você sabia que vocês dois eram anormais - o jeito como os grosseiros eram grosseiros demais e os simpáticos, simpáticos demais. As velhas e os velhos brancos que murmuravam 
e o encaravam, os homens negros que balançavam a cabeça para você, as mulheres negras com pena nos olhos, lamentando a sua falta de autoestima, seu desprezo por si mesma. (ADICHIE, 2017, p. 136)

Todas elas se fundamentam na relação do individual e do social: os dois estão em um relacionamento pessoal, todavia, fazem parte de uma sociedade que coloca as pessoas negras em um lugar de subalternidade: ela, como mulher negra, é oprimida, algo que não acontece com ele, como homem branco. Assim, os casais brancos e idosos os veem como incompatíveis, já que uma jovem negra não seria o suficiente para um rapaz branco. Os homens negros se sentem preteridos, e as mulheres negras veem Akunna com pena, como se ela tivesse se desprezando ao se relacionar com alguém que faz parte do grupo privilegiado que, muitas vezes, reforça a opressão racial e patriarcal.

Um dia, Akunna escreve para sua mãe, e a carta de resposta traz uma notícia triste: o pai da jovem havia morrido há cinco meses. Akunna, devastada, tenta se lembrar do que fez durante aquele tempo, enquanto não sabia do falecimento, e resolve retornar à Nigéria. $\mathrm{O}$ namorado se oferece para ir com ela, mas a jovem decide ir sozinha. Não se sabe se voltará aos Estados Unidos. Nesse sentido, a dor é a ruptura da diáspora e a retomada do laço. 
Desse modo, constatamos que essa personagem nigeriana no exterior está em uma condição diaspórica "feita de memórias e referências da terra de origem, reconstituída e reimaginada na distância espaçotemporal e de novas vivências no país hospedeiro, em confronto com os pertences culturais trazidos da terra de origem" (BRAGA, 2014, p. 36), além de ser um sujeito pós-colonial, pois é marcado por uma intensa inquietude e mobilidade, próprias da pós-colonialidade, tanto geográfica (deslocamento Nigéria-Estados Unidos), quanto simbólica (apresentada por meio de memórias e referências da terra natal, que são colocadas em confronto com suas experiências na terra estrangeira). Enfim, por último, como dissemos, os conflitos que surgem a partir da chegada na terra do hospedeiro (o racismo e a ignorância no que se refere à África), além do sexismo, marcam a interseccionalidade (AKOTIRENE, 2019) de opressões que a atingem como mulher, negra e imigrante africana.

\section{A VIOLÊNCIA CONTRA A MULHER NEGRA: RACISMO ESTRUTURAL E OPRESSÃO PATRIARCAL EM “MARIA"}

Maria da Conceição Evaristo de Brito nasceu em uma favela de Belo Horizonte, Minas Gerais, em 1946. É Mestre em Literatura Brasileira pela Pontifícia Universidade Católica 
do Rio de Janeiro e Doutora em Literatura Comparada pela Universidade Federal Fluminense. Em 1990, Conceição Evaristo publicou seu primeiro poema nos Cadernos Negros, editados pelo grupo paulista Quilombhoje. Desde então, publicou diversos poemas e contos nos Cadernos, além de dois romances, Ponciá Vicêncio (2003) e Becos da memória (2006); uma coletânea de poemas, Poemas da recordação (2008); e três livros de contos, Insubmissas lágrimas de mulheres (2011), Olhos d'água (2014) e Histórias de leves enganos e parecenças (2016).

O conto "Maria" compõe Olhos d'água (2014)르, obra vencedora do prêmio Jabuti em 2015. Neste conto, a autora apresenta as inúmeras violências, desigualdades e pobreza às quais a população afro-brasileira é submetida, em especial as mulheres negras (GALLINDO, 2018), que, como dissemos, estão em um lugar de subalternidade difícil de ser superado, devido ao racismo e ao sexismo. Tendo em vista que o racismo é um elemento que estrutura a sociedade brasileira e está enraizado em suas instituições, faz-se pertinente fazer algumas considerações sobre o racismo "à brasileira".

Abdias Nascimento (2017), em O genocídio do negro brasileiro, aborda sobre o brutal processo de colonização portuguesa, que, por vários meios, praticou o genocídio 1 A obra foi publicada em 2014, porém, a edição utilizada neste artigo é a de 2016. 
de pessoas negras, de suas culturas e religiões através de um racismo mascarado. Primeiramente, o autor inicia com o processo de colonização portuguesa e a imediata escravização dos negros, pois

o ponto de partida nos assinala a chamada
'descoberta' do Brasil pelos portugueses,
em 1500. A imediata exploração da
nova terra se iniciou com o simultâneo
aparecimento da raça negra, fertilizando
o solo brasileiro com suas lágrimas,
seu sangue, seu suor e seu martírio na
escravidão. (NASCIMENTO, 2017, p. 57)

Os frutos do trabalho escravo foram aproveitados unicamente pela aristocracia branca. Após a abolição da escravatura, em 1888, não houve nenhuma medida do Estado de inclusão da população negra no meio social, além de várias leis que tinham como objetivo impedir sua mobilidade social. Segundo Ribeiro (2018), no Brasil, após os quase quatro séculos de escravidão, em que as pessoas negras trabalharam para enriquecer as brancas, houve o incentivo da vinda de imigrantes europeus. Esses receberam trabalho renumerado e, muitas vezes, terras do Estado brasileiro, de modo que, se seus descendentes desfrutam de uma realidade confortável, é graças a essa ajuda inicial. Por outro lado, "para a população negra, não se criou mecanismos de inclusão. Das senzalas fomos para as favelas. 
Se hoje a maioria da população negra é pobre é por conta dessa herança escravocrata" (RIBEIRO, 2018, p. 72-73).

Essa herança se perpetua, também, por meio do racismo estrutural, pois perpassa os costumes, as atitudes, a mentalidade da nação devido ao processo de genocídio explicitado e do racismo institucional, uma vez que as instituições criam barreiras para a mobilidade social dos negros e seu acesso a espaços de poder. No caso das mulheres negras, essas questões raciais se conjugam com as de gênero através da interseccionalidade, pois as opressões estruturais oriundas de sociedades de matriz colonial se intercruzam e interagem simultaneamente (AKOTIRENE, 2019). O sistemático estupro das mulheres negras pelos colonizadores, exposto por Nascimento (2017), reverbera na sua hiperssexualização e desumanização nos dias atuais.

Essas opressões se refletem nas escrevivências de Conceição Evaristo. O conto "Maria" se inicia com a protagonista, uma mulher negra, esperando o ônibus há mais de meia hora no ponto. Através do narrador onisciente, notamos a condição social da personagem: "No dia anterior, no domingo, havia tido festa na casa da patroa. Ela levava para casa os restos. $\mathrm{O}$ osso do pernil e as frutas que tinham enfeitado a mesa. Ganhara as frutas e uma gorjeta. $\mathrm{O}$ osso, 
a patroa ia jogar fora" (EVARISTO, 2016, p. 39). A menção da patroa indica que Maria é uma empregada doméstica de baixa condição econômica, porque seu único meio de transporte é o ônibus, cuja passagem estava aumentando tanto que havia risco de não haver nem mesmo esse meio de locomoção. Ademais, a personagem fica somente com os restos do banquete da patroa. Assim, é perceptível a situação dessa classe no país: relegada a ficar com os restos, até mesmo o que é considerado lixo: "O osso, a patroa ia jogar fora". Percebemos que, no Brasil, a muitas mulheres negras são negadas oportunidades de emprego fora de serviços manuais, como observa Carneiro:

Segundo dados divulgados pelo Ministério do Trabalho e pelo Ministério da Justiça na publicação Brasil, gênero e raça, "as mulheres negras ocupadas em atividades manuais fazem um total de $79,4 \% "$. Destas, $51 \%$ estão alocadas no emprego doméstico e $28,4 \%$ são lavadeiras, passadeiras, cozinheiras serventes. (2011, p. 127 e 128, grifo da autora)

Mais uma vez, notamos discriminações atingindo simultaneamente essas mulheres, a exemplo de Maria, vítima de opressões estruturais que se intercruzam, vindas, como diz Ribeiro (2018), da herança escravocrata do país, que cria barreiras à ascensão e à mobilidade social de pessoas negras. 
No início da narrativa, vemos que, apesar do seu cansaço, Maria estava feliz, porque poderia usar a gorjeta para comprar remédio para a gripe de seus meninos e levar as frutas para eles: "As crianças nunca tinham comido melão. Será que os meninos iriam gostar de melão?" (EVARISTO, 2016, p. 40). As frutas parecem ser algo incomum, dado que as crianças nunca haviam experimentado melão. 0 contraste de classe entre Maria e sua patroa é ainda maior quando o leitor toma conhecimento de um corte na mão da personagem feito por uma faca a laser, objeto tecnológico: "A palma de uma de suas mãos doía. Tinha sofrido um corte, bem no meio, enquanto cortava o pernil para a patroa. Que coisa! Faca a laser corta até a vida!" (EVARISTO, 2016, p. 40).

Maria entra no ônibus e um homem paga a própria passagem e a dela. Ela o reconhece: é o pai de seu filho mais velho, de quem sente saudades. Narrada por meio do discurso indireto livre, uma conversa se desenrola entre eles aos cochichos, sem que um se virasse para o outro. O homem pergunta a ela sobre o menino, diz que sente saudades deles, se ela tinha tido outros filhos: "Ela teve mais dois filhos, mas não tinha ninguém também" (EVARISTO, 2016, p. 40). A partir disso, apreendemos que o fato de Maria ser mãe solo é resultado da solidão da mulher negra, 
a "independência" da mulher negra em consequência da irresponsabilidade autorizada e legitimada do homem pelo patriarcado. No que diz respeito à sua condição de mãe, Evaristo observa que na literatura brasileira hegemônica "à personagem negra feminina é negada a imagem de mulhermãe, perfil que aparece tantas vezes desenhado para as mulheres brancas em geral" (2009, p. 23). Porém, na sua escrita literária, em um contra-discurso, Maria aparece nesse papel.

Após a conversa aos cochichos entre Maria e o pai de seu primogênito, uma ação repentina dele muda o clima da narrativa: "Ela, ainda sem ouvir direito, adivinhou a fala dele: um braço, um beijo, um carinho no filho. E, logo após, levantou rápido sacando a arma. Outro lá atrás gritou que era um assalto" (EVARISTO, 2016, p. 41). Todos no ônibus ficaram em silêncio enquanto o outro homem recolhia os pertences dos passageiros, enquanto isso, Maria estava com muito medo, por causa dos três filhos: "Meu Deus, como seria a vida dos seus filhos? [...]. O comparsa de seu ex-homem passou por ela e não pediu nada" (EVARISTO, 2016, p. 41).

Os assaltantes desceram e um dos passageiros começou a insultar e acusar Maria:

Alguém gritou que aquela puta safada lá da frente conhecia os assaltantes. Maria 
se assustou. Ela não conhecia assaltante algum. Conhecia o pai de seu primeiro filho. Conhecia o homem que tinha sido dela e que ela ainda amava tanto. Ouviu uma voz: Negra safada, vai ver estava de coleio com os dois. (EVARISTO, 2016, p. 41, grifo da autora)

O machismo e o racismo nessas falas reforçam como a opressão patriarcal rebaixa a mulher e a violenta ("puta safada"), o que nos remete ao fato de que

[...] ser mulher não é apenas diferente de ser homem, como também implica inferioridade, desvalorização, opressão. Embora não haja espaço para se discutir a polissemia do conceito de opressão, entende-se necessário indicar, pelo menos, que o oprimido tem seu campo de opções reduzido, sendo objeto de um processo de dominação-exploração. (BENDA, 2016, grifo nosso)

Também há a reafirmação do racismo, através da marcação dela como "negra safada", indicando que sua negritude, assim como sua condição de mulher, denota inferioridade. O discurso de ódio direcionado a Maria, de modo gratuito, provém de opressões estruturais que a atingem duplamente, como mulher e negra, além de ser pobre, confirmando a assertiva de Carneiro (2016) acerca da perversa e cruel exclusão e marginalização sociais das mulheres negras, e, no caso desse conto, a violência sofrida por elas. 
Essa violência vai ganhando proporções cada vez maiores, com a repetição dos discursos de ódio até a incitação da violência física por meio do linchamento:

A primeira voz, a que acordou a coragem de todos, tornou-se um grito: Aquela puta, aquela negra safada estava com os ladrões! O dono da voz levantou e se encaminhou em direção à Maria. A mulher teve medo e raiva. Que merda! Não conhecia assaltante algum. Não devia satisfação a ninguém. Olha só, a negra ainda é atrevida, disse o homem, lascando o tapa no rosto da mulher. Alguém gritou: Lincha! Lincha! Lincha! (EVARISTO, 2016, p. 42, grifo da autora)

Maria perde até mesmo o direito de se defender, visto que o homem a chama de negra atrevida e lasca um tapa no seu rosto, mais uma vez afirmando sua superioridade como homem em uma sociedade patriarcal, racista e desigual. Logo, o lugar social de subalternidade de Maria, o Outro do outro, a desumaniza e a silencia estruturalmente (RIBEIRO, 2019; KILOMBA, 2019).

O motorista do ônibus para o veículo para defender Maria, além de outro rapaz (negro) falar a seu favor, mas ela é linchada brutalmente pelos passageiros. Uma agressão descrita de forma realista e crua, que demonstra a vulnerabilidade simbólica, social, cultural, histórica e de gênero da personagem: 
Lincha! Lincha! Lincha! Maria punha sangue pela boca, pelo nariz e pelos ouvidos. A sacola havia arrebentado e as frutas rolavam pelo chão. Será que os meninos iriam gostar de melão? Tudo foi tão rápido, tão breve, Maria tinha saudades de seu exhomem. [...]. Estavam todos armados com facas a laser que cortam até a vida. Quando o ônibus esvaziou, quando chegou a polícia, o corpo da mulher estava todo dilacerado, todo pisoteado. (EVARISTO, 2016, p. 42, grifo da autora)

Desse modo, o racismo e o sexismo chegam ao ápice, culminando no assassinato cruel e gratuito de Maria. Como diz Gonzalez,

quanto à mulher negra, que se pense em sua falta de perspectivas quanto à possibilidade de novas alternativas. Ser negra e mulher no Brasil, repetimos, é ser objeto de tripla discriminação, uma vez que os estereótipos gerados pelo racismo e pelo sexismo a colocam no mais alto nível de opressão. (GONZALEZ, 2016, p. 408)

A mulher negra, por ser duplamente inferiorizada (mulher e negra), é a errada, a culpada e deve pagar a conta, ela pagou. Maria pagou, com a vida. Seu corpo-peça, ainda é o tempo-lugar memorial da escravidão, seu corpo é a moeda que paga a conta do/pelo homem. Os pensamentos da personagem durante o linchamento a humaniza em meio a um ato de desumanização, pois ela pensa em seus filhos, 
nas frutas que ela levaria, no recado que precisava dar. A metáfora da faca a laser que corta até a vida é repetida três vezes ao longo do conto: ela remete às cirurgias à laser, muito recentes no tempo da narrativa, que cortam a vida (são também os abortos nas clínicas caras do Rio de Janeiro), mas também são as facas usadas nas madrugadas para assassinatos clandestinos na favela, no caso de rixas entre traficantes, e são os cortes do fio da vida sem corte. Essas realidades, em muitos casos, cercam a vida de pessoas negras no Brasil. Na última vez que a metáfora é usada, não é a faca da patroa que a corta (podendo indicar uma violência simbólica, social), mas são os passageiros do ônibus, seus semelhantes, aqueles que seguram facas que cortam e dizimam sua vida (violência física).

\section{CONSIDERAÇÕES FINAIS}

A partir dessas discussões e das análises dos contos, podemos reafirmar que as personagens femininas negras de diferentes diásporas africanas experienciam e manifestam (no sentido de manifesto, denúncia), em seu tempo-lugar, opressões estruturais relacionadas ao colonialismo, tais como o racismo, o sexismo e o classicismo (KILOMBA, 2019). De início, tanto Maria quanto Akunna são mulheres negras e, devido a isso, ocupam um lugar social e têm vivências 
que não são possíveis para homens (brancos ou negros) e para mulheres brancas (RIBEIRO, 2019; CARNEIRO, 2016; BERTH, 2018). As duas são vítimas da interseccionalidade (AKOTIRENE, 2019) de opressões de raça e de gênero: no caso de Maria, essa condição de dupla subalternidade resultou na violência verbal e simbólica, indicada em falas como "negra safada" e "a negra ainda é atrevida", chegando ao extremo do assassinato por linchamento (violência física); além de sua condição de empregada doméstica, no contexto brasileiro, estar associada ao racismo estrutural do país, que dificilmente oferece oportunidades de ascensão econômica e mobilidade social às pessoas negras. Ademais, Maria é a única que sustenta seus filhos, uma vez que o homem é desculpado pelo patriarcado de sua responsabilidade, causando, assim, a solidão da mulher negra; ela também é silenciada estruturalmente, tendo em vista que, ao tentar se defender, recebe um tapa na cara de um homem que a acusava. Sua experiência de opressão é semelhante à de muitas outras Marias brasileiras e manifesta o preço que essas mulheres pagam por serem negras em uma sociedade patriarcal, racista e desigual.

Por outro lado, Akunna também é vítima de dupla opressão: por ser mulher, sofre assédio de seu tio, e por ser 
negra, é discriminada em seu relacionamento com um rapaz branco, sendo vista como não digna de ser considerada sua namorada, além de receber perguntas ignorantes e racistas a respeito do seu cabelo, tais como: "Você usa pente?". Por ser um sujeito diaspórico pós-colonial, ou seja, que emigra da Nigéria (país recentemente independente, marcando a sua condição recente de pós-colonialidade) para os Estados Unidos, em busca de melhores condições de vida, ela enfrenta conflitos na terra hospedeira: a situação relacionada ao cabelo, por exemplo, não é uma questão na Nigéria, terra natal, país com a maior parte de sua população negra. Porém, o racismo e a ignorância presentes na terra hospedeira criam esse conflito. Além disso, Akunna, por ser imigrante africana, ouve uma série de estereótipos: se há casas e carros de verdade na África, sobre elefantes e safáris, entre outros, além de receber menos no restaurante onde trabalha como garçonete, dinheiro que mal dá para suas despesas, pois ela envia metade dele para seus familiares. Existe, ainda, o confronto entre os pertences culturais da terra de origem e os da terra hospedeira (BRAGA, 2014), como o estranhamento de receber presentes inúteis, a forma como os estadunidenses deixam muita comida no prato, etc. As experiências de opressão causam em Akunna a sensação de algo em volta de seu pescoço, que ameaça sufocá-la, mas 
a jovem não sucumbe. Sua trajetória manifesta os conflitos enfrentados por mulheres negras e imigrantes nigerianas.

A partir dessas constatações, notamos a confirmação da perspectiva de Grada Kilomba (2019) ao afirmar que mulheres negras, de diferentes diásporas africanas, compartilham experiências de opressão oriundas do colonialismo, já que as personagens analisadas, cada uma com suas vivências únicas e singulares, sofrem as violências simbólica, social, cultural e física por sua condição de sujeito-mulher-negra. Porém, não somente isso: elas também compartilham processos de resistência, uma rede de afetividade que ultrapassa a dimensão individual e chega ao empoderamento coletivo, de todo um grupo (BERTH, 2018). Maria, mulher negra, pobre e empregada doméstica resiste em um sistema que a oprime em todos os sentidos e em que a luta pela sobrevivência é diária. Apesar de ser assassinada e silenciada, Maria resiste e se empodera ao não se deixar sucumbir no cotidiano, e continuar trabalhando em um serviço considerado como subalterno, pois caso contrário nem ela tampouco seus filhos sobreviveriam. Akunna, por sua vez, não sucumbe, o pescoço está sufocado, com torcicolo, mas ela se ergue, mesmo com os obstáculos e opressões se intercruzando 
durante seu tempo na terra estrangeira. Na viagem da volta, em etnogênese de memória e subjetividade, Akunna volta, para ou da Nigéria.

Assim como as personagens, as autoras Chimamanda Adichie e Conceição Evaristo são sujeitos-mulheres-negras. Nesse sentido, Evaristo (2011) diz que o texto tem autoria, e ela, ao inventar, não se desvencilha de seu corpo-mulhernegra em vivência, e por ele, ela vive experiências que um corpo não-negro e não mulher jamais experimenta. Esse é o fundamento do conceito de escrevivência: a consciência do vivido que faz da escrita um lugar de afirmação de particularidades e especificidades do escritor (ALVES; SOUZA, 2018). Logo, a literatura hegemônica, composta principalmente por homens brancos, ao falar de e por pessoas negras, o faz sob uma ótica colonizadora, pois não pode saber das vivências dessa população, tendo em vista seu lugar de privilégio social.

Diante disso, notamos a importância do lugar de fala (RIBEIRO, 2019) de quem escreve, pois existe uma hierarquização de saberes resultante da hierarquia social, condição que impõe um lugar de silenciamento estrutural a grupos sociais subalternizados e dá legitimidade ao conhecimento hegemônico (feitos por homens brancos). 
As escrevivências de Adichie e de Evaristo são importantes para possibilitar voz e visibilidade a sujeitos que foram consideradosimplícitos dentro da normatização hegemônica (masculina e branca), promovendo, dessa maneira, uma multiplicidade de vozes através do "deslocamento do pensamento hegemônico e a ressignificação das identidades, sejam de raça, gênero, classe para que se pudesse construir novos lugares de fala" (RIBEIRO, 2019, p. 42-43). Suas personagens, em especial as analisadas neste trabalho, são representadas de modo humanizado e com suas idiossincrasias, assim como suas experiências de opressão não são amenizadas ou diminuídas. Isso abre as portas para o entendimento da posição das mulheres negras na base da pirâmide social e a necessidade de enfrentamentos dessa condição.

Assim como os conceitos de lugar de fala e de interseccionalidade, o de empoderamento é uma ferramenta de combate ao silenciamento epistêmico que foi ressignificado pelo Feminismo Negro (BERTH, 2018). De acordo com esta autora, tendo como fator limítrofe a permanência na base da pirâmide social, o resgate desse conceito mostra-se fundamental na luta pela quebra da formação hegemônica dessa pirâmide. Segundo Berth, 
"podemos chamar de resgate, pois não é novidade para os movimentos de mulheres negras, a necessidade de busca por processo de empoderamento como condição de sobrevivência" (2018, p. 103). Sob esse viés, para a autora, o empoderamento visa uma postura de enfrentamento da opressão para a eliminação da situação injusta e equalização de existências em sociedade. A partir disso, constatamos que a literatura produzida por Adichie e Evaristo se caracteriza como um processo de empoderamento, porque, ao se ter mulheres negras falando sobre si e seus corpos, há uma possibilidade de romper com o silenciamento epistêmico, bem como uma postura de enfrentamento de opressões para que possa haver a libertação social de todo um grupo, por várias frentes de atuação, incluindo a emancipação intelectual (BERTH, 2018, p. 34). Para Evaristo, "a nossa escrevivência não pode ser lida como histórias para 'ninar os da casa grande' e sim para incomodá-los em seus sonos injustos" (2007, p. 21), ou seja, a mudança na injustiça parte do incômodo.

Por fim, é relevante analisar a importância do Feminismo Negro nesse processo de emancipação e ressignificação social por parte de mulheres negras. A perspectiva feminista negra nomeia opressões de raça, classe e gênero, sem 
hierarquizá-las, mas pensando em como a interação dessas categorias refletem sobre os sujeitos subalternizados, em especial as mulheres negras, antítese da masculinidade e da branquitude (RIBEIRO, 2019; KILOMBA, 2019). Ela se faz pertinente neste artigo na medida em que tais opressões interagem simultaneamente no que diz respeito às personagens femininas de Adichie e de Evaristo, sendo que não há primazia de uma em relação às outras, pois todas têm efeitos negativos nas vítimas. Neste sentido, vemos a importância do Feminismo Negro, pois ele atende às especificidades de mulheres sujeitas a diferentes tipos de opressão, além de oferecer ferramentas conceituais para que se possa romper com a cisão criada numa sociedade desigual, racista e heterossexista. Assim, as autoras, ao romperem com o regime de autorização discursiva, tornam-se sujeitos e não objetos, como diz Kilomba sobre a escrita como um ato político de resistência: "enquanto escrevo, eu me torno narradora e a escritora da minha própria realidade, a autora e autoridade na minha própria história. Nesse sentido, eu me torno a oposição absoluta do que o projeto colonial predeterminou" (2019, p. 28). Dessa maneira, enquanto mulheres negras e escritoras, elas reclamam o seu direito à voz e à existência digna: por meio de sua produção literária, elas afirmam um contra- 
discurso às vozes que silenciaram e desumanizaram corpos negros, assim como emancipam e reconstroem seu lugar dentro da sociedade.

\section{REFERÊNCIAS}

ADICHIE, Chimamanda Ngozi. The Danger of a Single Story. TEDGlobal, jul. 2009. Disponível em: ted.com/talks/chimamanda adichie the danger of a single story. Acesso em: 05 jun. 2019.

ADICHIE, Chimamanda Ngozi. We Should All Be Feminists. TEDGlobal, abr. 2013. Disponível em: ted.com/talks/chimamanda ngozi adichie we should_all_be feminists. Acesso em: 05 jun. 2019.

ADICHIE, Chimamanda Ngozi. Americanah. Tradução de Julia Romeu. Rio de Janeiro: Companhia da Letras, 2014.

ADICHIE, Chimamanda Ngozi. Hibisco roxo. Tradução de Julia Romeu . São Paulo: Companhia das letras, 2011.

ADICHIE, Chimamanda Ngozi. Meio-sol amarelo. Tradução de Beth Vieira. São Paulo: Companhia das letras, 2008.

ADICHIE, Chimamanda Ngozi. No seu pescoço. Tradução de Julia Romeu. São Paulo: Companhia das letras, 2017.

AKOTIRENE, Carla. Interseccionalidade. São Paulo: Sueli Carneiro; Pólen, 2019. ALVES, Ana Claudia Oliveira Neri; SOUZA, Elio Ferreira de. A escrevivência de Chimamanda Ngozi Adichie em Americanah: diálogos com Conceição Evaristo. Cadernos Cajuína. Teresina, v. 3, n. 2, p. 85-94, 2018.

BENDA, Laura Rodrigues. A importância de ser feminista no Brasil do golpe. Justificando, 14 dez. 2016. Disponível em: http://www. justificando.com/2016/12/14/importancia-de-ser-feminista-no-brasildo-golpe/. Acesso em: 5 fev. de 2021.

BRAGA, Cláudio Roberto Vieira. A literatura movente de Chimamanda Adichie: pós-colonialidade, descolonização cultural e diáspora. Brasília: Editora Universidade de Brasília, 2019. 
BRAGA, Cláudio Roberto Vieira. Os contos diaspóricos de Chimamanda Ngozi Adichie: representações da experiência nigeriana nos Estados Unidos. In: OLIVEIRA, Paulo César; CARREIRA, Shirley de Souza Gomes (Orgs.). Diásporas e deslocamentos: travessias críticas. Rio de Janeiro: FGV, p. 31-54, 2014.

BERTH, Joice. O que é empoderamento? Belo Horizonte: Letramento, 2018. CARNEIRO, Sueli. Racismo, sexismo e desigualdade no Brasil. São Paulo: Selo negro, 2011.

CARNEIRO, Sueli. Mulheres em movimento. In: RODRIGUES, Carla; BORGES, Luciana; RAMOS, Tania Regina Oliveira (Org.). Problemas de gênero (ensaios brasileiros contemporâneos). Rio de Janeiro: Funarte, p. 149-168, 2016.

DAVIS, Angela. Mulheres, raça e classe. São Paulo: Boitempo, 2016. EVARISTO, Conceição. Da grafia-desenho de minha mãe um dos lugares de nascimento da minha escrita. In: ALEXANDRE, Marcos Antônio (Org.). Representações performáticas brasileiras: teorias, práticas e suas interfaces. Belo Horizonte: Mazza Edições, p. 16-21, 2017.

EVARISTO, Conceição. Literatura negra: uma poética de nossa afrobrasilidade. SCRIPTA. Belo Horizonte, v. 13, n. 25, p. 17-31, 20 semestre de 2009. Disponível em: http://periodicos.pucminas.br/index.php/ scripta/article/viewFile/4365/4510. Acesso em: 16 jul. 2019.

EVARISTO, Conceição. Becos da memória. Rio de Janeiro: Pallas, 2017. EVARISTO, Conceição. Histórias de leves enganos e parecenças. 5. ed. Rio de Janeiro: Malê, 2017.

EVARISTO, Conceição. Insubmissas lágrimas de mulheres. Rio de Janeiro: Malê, 2016.

EVARISTO, Conceição. Olhos d'água. Rio de Janeiro: Pallas, 2016.

EVARISTO, Conceição. Ponciá Vicêncio. Rio de Janeiro: Pallas, 2017.

EVARISTO, Conceição. Poemas da recordação e outros movimentos. 5. ed. Rio de Janeiro: Malê, 2017.

GALLINDO, Ícaro Felipe Santiago. Identidade negra e violência contra a mulher em Olhos d'água, de Conceição Evaristo. 2018. Trabalho de 
Conclusão de Curso (Licenciatura em Letras) - Departamento de Letras, Universidade Federal Rural de Recife, Recife, 2018.

GONZALEZ, Lélia. Racismo e sexismo na cultura brasileira. Revista Ciências Sociais Hoje, v. 2, n. 1, p. 223-244, 1984.

GONZALEZ, Lélia. Por um feminismo afrolatinoamericano. Revista Isis Internacional. Santiago, v. 9, p. 133-141, 1988.

GONZALEZ, Lélia. A mulher negra na sociedade brasileira: uma abordagem político-econômica. In: RODRIGUES, Carla; BORGES, Luciana; RAMOS, Tania Regina Oliveira (Org.). Problemas de gênero (ensaios brasileiros contemporâneos). Rio de Janeiro: Funarte, p. 399-416, 2016. HALL, Stuart. A identidade cultural na pós-modernidade. Rio de Janeiro: DP\&A, 2006.

HALL, Stuart. Da diáspora: identidades e mediações culturais. Belo Horizonte: Editora UFMG, 2009.

KILOMBA, Grada. Memórias da plantação: episódios de racismo cotidiano. Rio de Janeiro: Cobogó, 2019.

MACHADO, Bárbara Araújo. "Escre(vivência)": a trajetória de Conceição Evaristo. In: História Oral, v. 17, n. 1, p. 243-265, janeiro/junho de 2014. Disponível em: http://revista.historiaoral.org.br/index.php?journal=rho\& page=article\&op=view\&path\%5B\%5D=343. Acesso em: 16 jul. 2019. NASCIMENTO, Abdias. O genocídio do negro brasileiro: processo de um racismo mascarado. 2. ed. São Paulo: Perspectiva, 2017. RIBEIRO, Djamila. A questão das mulheres negras precisa ser central. In: RODRIGUES, Carla; BORGES, Luciana; RAMOS, Tania Regina Oliveira (Org.). Problemas de gênero (ensaios brasileiros contemporâneos). Rio de Janeiro: Funarte, p. 21-26, 2016.

RIBEIRO, Djamila. Quem tem medo do feminismo negro? São Paulo: Companhia das Letras, 2018.

RIBEIRO, Djamila. Lugar de fala. São Paulo: Sueli Carneiro; Pólen, 2019. 


\section{Lorrany Andrade da Cruz}

Mestranda em Letras e Linguística (Estudos Literários) pelo Programa de Pós-Graduação em Letras e Linguística da UFG, com bolsa CAPES.

Participa do grupo de pesquisa "Estudos sobre a narrativa brasileira contemporânea", liderado pelo Prof. Dr. Flávio Pereira Camargo, da UFG. Lattes: http://lattes.cnpq.br/6720218824631617

Email: lorrany005@discente.ufg.br

ORCID iD: https://orcid.org/0000-0003-1647-2582

\section{Flávio Pereira Camargo}

Doutor em Literatura pela UnB (2010) e em Letras e Linguística (Estudos Literários) pela UFG (2012), com Pós-doutorado em Estudos Literários pela UFMG (2010).

É professor Associado de Literatura Brasileira da Faculdade de Letras da UFG/Regional Goiânia, com atuação na Graduação e na Pós-Graduação em Letras e Linguística.

É líder do grupo de pesquisa "Estudos sobre a narrativa brasileira contemporânea" (CNPq/UFG) e membro do GT "Homoculura e Linguagens" vinculado à Anpoll.

Lattes: http://lattes.cnpq.br/5015485726957185

E-mail: flaviocamargo@ufg.br

ORCID iD: https://orcid.org/0000-0001-9116-2432 